\title{
Longer Walking Distance, More Fat, Better Survival: Prognostic Indicators of Liver Cirrhosis
}

\author{
Piero Portincasa $^{1}$, Agostino Di Ciaula ${ }^{1}$, David Q.-H. Wang ${ }^{2}$
}

1) Department of Biomedical

Sciences and Human

Oncology, Clinica Medica A. Murri, University of Bari Aldo Moro Medical School, Bari, Italy;

2) Department of Medicine and Genetics, Division of Gastroenterology and Liver Diseases, Marion Bessin Liver Research Center, Einstein-Mount Sinai Diabetes Research Center, Albert Einstein College of Medicine, Bronx, NY 10461, USA

\footnotetext{
Address for correspondence: Prof. Piero Portincasa, MD, $\mathrm{PhD}$

Clinica Medica Augusto Murri, Department of Biomedical Sciences and Human Oncology, University of Bari Medical School Piazza Giulio Cesare 11, 70124 Bari, Italy piero.portincasa@uniba.it
}

Received: 05.01.2021 Accepted: 08.01.2021
Liver cirrhosis is the late stage of progressive hepatic fibrosis and chronic liver disease, leading to distortion of the architecture of the liver and growth of regenerative nodules. Cirrhosis is characterized by an important burden of disease and decreased life expectancy. The prognosis of cirrhosis is highly variable and is influenced by etiology, severity, presence of complications, and comorbid diseases. Mortality rates are high when clinical decompensation becomes apparent with ascites, variceal hemorrhage, encephalopathy, portal hypertensive gastropathy, spontaneous bacterial peritonitis, hepatorenal syndrome, hepatopulmonary syndrome, porto-pulmonary syndrome, cirrhotic cardiomyopathy, hepatocellular carcinoma, and portal vein thrombosis. Upon decompensation, cirrhosis becomes lethal or requires liver transplantation. In the United States cirrhosis accounts for almost 50,000-66,000 deaths, of which 18,000-19,500 are attributable to liver cancer $[1,2]$.

Secondary prevention and identification of complications in cirrhotic patients have a significant impact on the prognosis, and great attention should be paid to regular screening for esophageal varices, hepatocellular carcinoma, and prudent diuresis, as well as the judicious use of proton pump inhibitors to prevent spontaneous bacterial peritonitis, and treatment of infections predisposing to spontaneous bacterial peritonitis and hepatic encephalopathy. Avoiding sedatives and treating electrolyte disturbances, i.e. hypokalemia and hyponatremia, could prevent hepatic encephalopathy. In addition, avoiding nephrotoxic agents and aggressive diuresis can prevent hepatorenal syndrome.

In this context, the prediction of both liver decompensation and mortality risk is a challenging task in clinical medicine, including planning optimal management of disease, improving the survival rate, and solving the best drug treatment. Based on clinical information and laboratory tests, two commonly used models to predict the prognosis of patients with cirrhosis are (i) the Child-Pugh classification that is based on serum albumin and bilirubin, ascites, encephalopathy, and prothrombin time; and (ii) the Model for End-Stage Liver Disease (MELD) that is based on bilirubin levels, creatinine, INR, and the etiology of cirrhosis. A Child-Pugh score of 10 to 15 refers to class C, indicating decompensated cirrhosis, and the score has been validated by the post-abdominal surgery mortality rate, surgical risk, survival rate, and the likelihood of the development of complications of cirrhosis, such as variceal hemorrhage [3]. The MELD score, or more recently the MELD-sodium (MELD$\mathrm{Na}$ ) score, plays a role in prioritizing patients waiting for liver transplantation. MELD could also predict the prognosis of patients with chronic liver disease in a non-transplant setting [4-6]. According to a systematic review, the median survival time is $\leq 6$ months in patients with decompensated cirrhosis and with a Child-Pugh score $\geq 12$, or a MELD score $>21$ [7]. However, neither of these two models takes into account the level of physical performance of patients with cirrhosis and its close relationship with the nutritional status and malnutrition. Several contributing factors to cirrhosis (e.g., due to insufficient dietary intake, abnormal digestion and absorption, and dysfunctional lipid and energy metabolism) can impair lipid, protein, and carbohydrate metabolism and lead to adverse consequences of the disease [8]. Protein calorie malnutrition occurs in about $20 \%$ of patients with compensated cirrhosis and in $50-100 \%$ of patients with decompensated cirrhosis [8-12], and liver disease is associated with changes in the composition of body compartments, i.e., water, fat, and muscle, reflecting adverse events $[13,14]$. Protein calorie malnutrition is associated with the development of variceal bleeding and ascites, higher morbidity and mortality from surgery, lower survival rate, and worsen hepatic function [10, 15-20]. 
Appropriate nutritional assessment of patients with cirrhosis is essential to detect and correct the macronutrient and micronutrient imbalance that could affect morbidity and mortality. The best performance for nutritional assessment is achieved in decompensated (Child-Pugh C) cirrhosis with a body mass index of $<18.5 \mathrm{~kg} / \mathrm{m}^{2}$. At this stage, it is helpful to record a complete medical history of weight changes, food intake, gastrointestinal symptoms, severity of cirrhosis, and micronutrient deficiency. Physical examination should investigate the presence of ascites and muscle waste (quadriceps and deltoids), as well as loss of subcutaneous fat (triceps and chest). In particular, sarcopenia and adipopenia are functional predictors of the clinical prognosis of liver cirrhosis, and at the same time, they are also powerful indicators of the quality of life of patients with cirrhosis. Laboratory analysis may find that creatinine is reduced because hepatic creatine synthesis and muscle mass are decreased, while the renal tubular creatinine secretion increases. Other proteins synthetized in the liver also decrease in cirrhosis, such as serum transferrin, pre-albumin, albumin, and coagulation factors (international normalized ratio, INR). With increasing liver dysfunction, there could be a vitamin $\mathrm{D}$ deficiency [21]. Water-soluble vitamins, i.e., folate and vitamin B12, and mineral deficiency are also informative about the nutritional status. If there are macro- and micronutrient deficiencies, supplementation of nutrients is needed to correct them, and this approach could reduce the risk of infection, decrease in-hospital mortality, and improve liver function parameters [22-25]. Anthropometric assessment also provides information about body fat and lean tissue storage, mid-arm muscle circumference, and skinfold thickness [26], which is indeed related to the survival of patients with cirrhosis $[27,28]$. The measurement of sarcopenia and muscle mass is usually done by different methods, including anthropometry, DEXA, CT scan, and bioelectrical impedance analysis. The finding of sarcopenia had a good correlation with pretransplant morbidity and mortality throughout the studies [29-31]. Muscle strength can predict malnutrition, which can be achieved with handgrip dynamometer [32], as well as the 6-minute walk test (6MWT) [27, 29, 33, 34].

In this issue, Henrique et al. [35] used the 6MWT as a predictor of the risk of clinical decompensation in patients with liver cirrhosis of several etiologies. The 6MWT measures the distance walked on a level surface in six minutes and provides useful information for clinical assessment of several advanced conditions involving heart, lung, and liver functions (Table I) [36]. For example, a shorter distance (less or equal to $300 \mathrm{~m}$ ) is consistent with more severe heart failure, and an increased risk of death [37].

In their prospective cohort study, the authors [35] defined decompensation as one of the following manifestations: jaundice, ascites, bleeding from oesophageal varices, hepatic encephalopathy, or spontaneous bacterial peritonitis. They recruited 55 patients (mean age 56.3 years, 65\% men, 65\% Child-Pugh class A, meaning compensated cirrhosis) with a follow-up of 3, 6, 9, and 12 months after baseline 6MWT, and recorded the presence of decompensation and requirement of hospitalization. After setting a clinical threshold (with $64 \%$ sensitivity and $82 \%$ specificity) that can predict clinical decompensation, the non-decompensated outcome rates for patients who walk less than or greater than $401.8 \mathrm{~m}(\mathrm{p}<0.001)$ during walking are $30 \%$ and $75 \%$, respectively. As already recognized in patients with heart failure or chronic obstructive pulmonary disease (COPD), the authors suggest that the 6MWT (specific cut-off value of $401.8 \mathrm{~m}$ for compensated cirrhotic patients) should be added to the clinical assessment of patients with cirrhosis to predict the risk of decompensation, not just mortality $[44,47]$.

As mentioned earlier, in liver cirrhosis, 6MWT plus physical frailty represents a valuable tool for assessing nutritional status and muscle function [29]. 6MWT is easy to perform in a clinical setting and does not require extensive training or equipment. Nevertheless, some staff members need to be trained to administer the 6MWT, and there are not always trained personnel in the ward [46]. In addition, further research is required to confirm the $6 \mathrm{MWT}$ validity in the setting of cirrhotic patients without decompensation, in addition to the reported applications (Table I). In clinical medicine, compared with existing tools, it is important to test whether novel diagnostic tools can bring other clinically relevant information. In this respect, compared with the existing Child-Pugh score, 6MWT should bring more information, and be validated in a larger number of patients with similar or different causes of cirrhosis, in addition to alcohol-related liver disease, chronic viral hepatitis, and nonalcoholic steatohepatitis, through a longer follow-up [48]. Further prospective studies are required to confirm whether 6MWT performs well in Child-Pugh class A and class B patients. Henrique et al. [35] confirm that the latter group has lower levels of albumin, higher levels of bilirubin, and higher INR, and is more predominant (54\%) in the decompensated group as compared with the compensated group (22\%). The finding that the group with alcohol-related liver cirrhosis, rather than viral-related cirrhosis, is more prone

Table I. Clinical use of the 6-minute walk test (6MWT) [36]

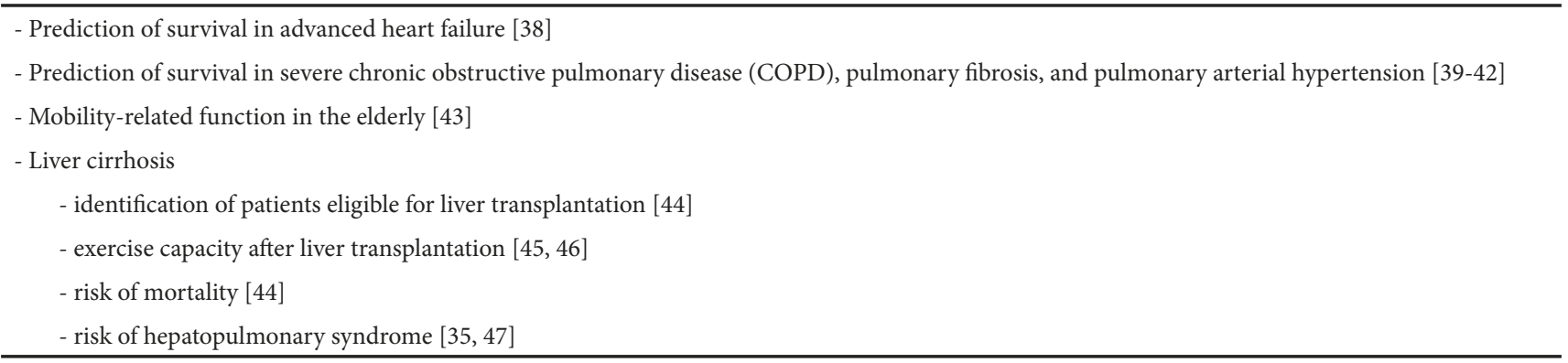


to decompensation, also deserves confirmation. Another point to investigate is the hospitalization rate relative to the $6 \mathrm{MWT}$ results. This finding stands for both cirrhotic patients after liver transplantation [46] and patients with COPD, because a $6 \mathrm{MWT}$ of $<200 \mathrm{~m}$ can predict both hospitalization and mortality $[49,50]$. When it is confirmed that a shorter walking distance can predict more hospitalizations, the evaluation might bring useful information about disease burden and additional costs, as has been seen in other situations, such as patients with chronic heart failure [38] and COPD [39-42]. In conclusion, the study of Henrique et al. [35] suggests that clinical decompensation is related to reduced exercise capacity, as assessed by 6MWT. Of note, as pointed out by the authors, when interpreting the test results, one should also consider the role of sarcopenia, physical inactivity [44], fatigue, change in skeletal muscle mass in liver cirrhosis [46]. In their study, few patients with cirrhosis were unable to complete the protocol or were not able to perform 6MWT. The presence of frailty and disability may decrease the effectiveness of the test, as observed in a subgroup of patients after liver transplantation [46].

In another paper in this issue, De Luca et al. [51] performed a clinical study to investigate the prevalence of malnutrition and its impact on mortality in 110 patients with cirrhosis and primary ascites. In addition to the presence of sarcopenia-related frailty, the adipose tissue compartment also plays a key role in the prognosis of patients with cirrhosis, which is related to the comprehensive assessment of the nutritional status of these subjects. After diagnostic paracentesis, patients were followed up for 24 months to assess the outcome. The authors focused, in particular, on the impact of malnutrition on mortality and on the relationship between malnutrition and spontaneous bacterial peritonitis. The prevalence of malnutrition varied from $30.9 \%$ to $40 \%$ and to $67.3 \%$ based to corrected body mass index, upper mid-arm fat area, and upper mid-arm muscle area, respectively. Survival rate was $68.1 \%, 59.3 \%, 45.1 \%$, and $24.2 \%$ at 3, 6, 12, and 24 months, respectively. By multivariate analysis, spontaneous bacterial peritonitis, MELD, and adipopenia, but not sarcopenia were the factors which are independently associated with mortality.Adipopenia also correlated with spontaneous bacterial peritonitis. The results from the cited study confirm that malnutrition is a common fellow traveler with liver cirrhosis, both in terms of sarcopenia and adipopenia (67.3\% and $40 \%$ of the enrolled patients, respectively), and that the predictive value of adipopenia on mortality is comparable to a high MELD score.

Taken together, the studies from Henrique et al. [35] and De Luca et al. [51] point out that decreased exercise and performance capacity occur simultaneously with the progressive reduction in the liver function, as a corollary to impaired nutritional status. The loss not only in skeletal muscle but also in the adipose tissue compartment plays a critical role in increasing the risk of decompensation, complications (i.e., spontaneous bacterial peritonitis), and mortality. These results are in line with those from a previous study demonstrating an inverse correlation between the hepatic venous pressure gradient (and, thus, the severity of portal hypertension), and the amount of adipose tissue. However, this correlation was not evident when imaging markers of sarcopenia were considered. In patients with compensated cirrhosis, lower visceral adipose tissue index was related to 12 -months decompensation. In patients with decompensated cirrhosis, the intramuscular adipose tissue index was independently associated with mortality [52].

From a clinical point of view, the adequate assessment of the adipose tissue compartment in patients with liver cirrhosis should be paralleled with the analysis of other prognostic indicators, and may be easily checked by a specific, standardized, reproducible and non-invasive technique such as ultrasonography [53]. Finally, in addition to the availability of tools that can predict the clinical outcome and mortality of patients with cirrhosis, i.e., secondary and tertiary prevention, a policy pointing to possible primary prevention of frailty [54] should be also considered in patients with advanced liver diseases.

Conflicts of interest: None to declare.

Authors' contribution: P.P., A.Di-C., D.Q.-H.W. designed the work, contributed to the draft and agreed on the final version.

\section{REFERENCES}

1. Asrani SK, Larson JJ, Yawn B, Therneau TM, Kim WR. Underestimation of liver-related mortality in the United States. Gastroenterology 2013;145:375-382.e1-2. doi:10.1053/j.gastro.2013.04.005

2. Murray CJ, Atkinson C, Bhalla K, et al. The state of US health, 1990-2010: burden of diseases, injuries, and risk factors. JAMA 2013;310:591-608. doi:10.1001/jama.2013.13805

3. de Franchis R, Primignani M. Why do varices bleed? Gastroenterol Clin North Am 1992;21:85-101.

4. Kamath PS, Wiesner RH, Malinchoc M, et al. A model to predict survival in patients with end-stage liver disease. Hepatology 2001;33:464-470.

5. Terra C, Guevara M, Torre A, et al. Renal failure in patients with cirrhosis and sepsis unrelated to spontaneous bacterial peritonitis: value of MELD score. Gastroenterology 2005;129:1944-1953. doi:10.1053/j. gastro.2005.09.024

6. Kim MS, Kato TS, Farr M, et al. Hepatic dysfunction in ambulatory patients with heart failure: application of the MELD scoring system for outcome prediction. J Am Coll Cardiol 2013;61:2253-2261. doi:10.1016/j.jacc.2012.12.056

7. Salpeter SR, Luo EJ, Malter DS, Stuart B. Systematic review of noncancer presentations with a median survival of 6 months or less. Am J Med 2012;125:512.e1-e16. doi:10.1016/j.amjmed.2011.07.028

8. Cheung K, Lee SS, Raman M. Prevalence and mechanisms of malnutrition in patients with advanced liver disease, and nutrition management strategies. Clin Gastroenterol Hepatol 2012;10:117-125. doi:10.1016/j.cgh.2011.08.016

9. Crawford DH, Shepherd RW, Halliday JW, et al. Body composition in nonalcoholic cirrhosis: the effect of disease etiology and severity on nutritional compartments. Gastroenterology 1994;106:1611-1617. doi:10.1016/0016-5085(94)90418-9

10. Lautz HU, Selberg O, Korber J, Burger M, Muller MJ. Protein-calorie malnutrition in liver cirrhosis. Clin Investig 1992;70:478-486. doi:10.1007/BF00210228

11. DiCecco SR, Wieners EJ, Wiesner RH, Southorn PA, Plevak DJ, Krom RA. Assessment of nutritional status of patients with end-stage liver disease undergoing liver transplantation. Mayo Clin Proc 1989;64:95102. doi:10.1016/s0025-6196(12)65308-7 
12. Hehir DJ, Jenkins RL, Bistrian BR, Blackburn GL. Nutrition in patients undergoing orthotopic liver transplant. JPEN J Parenter Enteral Nutr 1985;9:695-700. doi:10.1177/0148607185009006695

13. Prijatmoko D, Strauss BJ, Lambert JR, et al. Early detection of protein depletion in alcoholic cirrhosis: role of body composition analysis. Gastroenterology 1993;105:1839-1845. doi:10.1016/00165085(93)91083-t

14. Mendenhall CL, Tosch T, Weesner RE, et al. VA cooperative study on alcoholic hepatitis. II: Prognostic significance of protein-calorie malnutrition. Am J Clin Nutr 1986;43:213-218. doi:10.1093/ ajcn/43.2.213

15. Shaw BW Jr, Wood RP, Gordon RD, Iwatsuki S, Gillquist WP, Starzl TE. Influence of selected patient variables and operative blood loss on six-month survival following liver transplantation. Semin Liver Dis 1985;5:385-393. doi:10.1055/s-2008-1040637

16. Porayko MK, DiCecco S, O'Keefe SJ. Impact of malnutrition and its therapy on liver transplantation. Semin Liver Dis 1991;11:305-314. doi:10.1055/s-2008-1040448

17. Moller S, Bendtsen F, Christensen E, Henriksen JH. Prognostic variables in patients with cirrhosis and oesophageal varices without prior bleeding. J Hepatol 1994;21:940-946. doi:10.1016/s01688278(05)80599-9

18. Siriboonkoom W, Gramlich L. Nutrition and chronic liver disease. Can J Gastroenterol 1998;12:201-207. doi:10.1155/1998/196047

19. Cabre E, Gassull MA. Nutritional and metabolic issues in cirrhosis and liver transplantation. Curr Opin Clin Nutr Metab Care 2000;3:345-354 doi:10.1097/00075197-200009000-00004

20. Manguso F, D’Ambra G, Menchise A, Sollazzo R, D’Agostino L. Effects of an appropriate oral diet on the nutritional status of patients with HCVrelated liver cirrhosis: a prospective study. Clin Nutr 2005;24:751-759. doi:10.1016/j.clnu.2005.02.010

21. Konstantakis C, Tselekouni P, Kalafateli M, Triantos C. Vitamin D deficiency in patients with liver cirrhosis. Ann Gastroenterol 2016;29:297-306. doi:10.20524/aog.2016.0037

22. de Ledinghen V, Beau P, Mannant PR, et al. Early feeding or enteral nutrition in patients with cirrhosis after bleeding from esophageal varices? A randomized controlled study. Dig Dis Sci 1997;42:536-541. doi:10.1023/a:1018838808396

23. Fan ST, Lo CM, Lai EC, Chu KM, Liu CL, Wong J. Perioperative nutritional support in patients undergoing hepatectomy for hepatocellular carcinoma. N Engl J Med 1994;331:1547-1552. doi:10.1056/NEJM199412083312303

24. Kearns PJ, Young H, Garcia G, et al. Accelerated improvement of alcoholic liver disease with enteral nutrition. Gastroenterology 1992;102:200-205. doi:10.1016/0016-5085(92)91801-a

25. Cabre E, Gonzalez-Huix F, Abad-Lacruz A, et al. Effect of total entera nutrition on the short-term outcome of severely malnourished cirrhotics. A randomized controlled trial. Gastroenterology 1990;98:715-720. doi:10.1016/0016-5085(90)90293-a

26. Frisancho AR. New norms of upper limb fat and muscle areas for assessment of nutritional status. Am J Clin Nutr 1981;34:2540-2545. doi:10.1093/ajcn/34.11.2540

27. Figueiredo FA, Dickson ER, Pasha TM, et al. Utility of standard nutritional parameters in detecting body cell mass depletion in patients with end-stage liver disease. Liver Transpl 2000;6:575-581. doi:10.1053/ jlts. 2000.9736

28. Gunsar F, Raimondo ML, Jones S, et al. Nutritional status and prognosis in cirrhotic patients. Aliment Pharmacol Ther 2006;24:563-572. doi:10.1111/j.1365-2036.2006.03003.x
29. Tandon P, Raman M, Mourtzakis M, Merli M. A practical approach to nutritional screening and assessment in cirrhosis. Hepatology 2017;65:1044-1057. doi:10.1002/hep.29003

30. European Association for the Study of the Liver. EASL Clinical Practice Guidelines on nutrition in chronic liver disease. J Hepatol 2019;70:172193. doi:10.1016/j.jhep.2018.06.024

31. van Vugt JL, Levolger S, de Bruin RW, van Rosmalen J, Metselaar HJ, IJzermans JN. Systematic Review and Meta-Analysis of the Impact of Computed Tomography-Assessed Skeletal Muscle Mass on Outcome in Patients Awaiting or Undergoing Liver Transplantation. Am J Transplant 2016;16:2277-2292. doi:10.1111/ajt.13732

32. Alvares-da-Silva MR, Reverbel da Silveira T. Comparison between handgrip strength, subjective global assessment, and prognostic nutritional index in assessing malnutrition and predicting clinical outcome in cirrhotic outpatients. Nutrition 2005;21:113-117. doi:10.1016/j.nut.2004.02.002

33. Mendenhall CL, Moritz TE, Roselle GA, et al. Protein energy malnutrition in severe alcoholic hepatitis: diagnosis and response to treatment. The VA Cooperative Study Group \#275. JPEN J Parenter Enteral Nutr 1995;19:258-265. doi:10.1177/0148607195019004258

34. Andersen H, Borre M, Jakobsen J, Andersen PH, Vilstrup H. Decreased muscle strength in patients with alcoholic liver cirrhosis in relation to nutritional status, alcohol abstinence, liver function, and neuropathy. Hepatology 1998;27:1200-1206. doi:10.1002/hep.510270503

35. Henrique DMN, Malaguti C, Limonge TM, et al. Six-Minute Walking Test as a Predictor of Clinical Decompensation in Patients with Cirrhosis. J Gastrointestinal Liver disease 2021;30. doi:10.15403/jgld3122

36. ATS Committee on Proficiency Standards for Clinical Pulmonary Function Laboratories. ATS statement: guidelines for the six-minute walk test. Am J Respir Crit Care Med 2002;166:111-117. doi:10.1164/ ajrccm.166.1.at1102

37. Arslan S, Erol MK, Gundogdu F, et al. Prognostic value of 6-minute walk test in stable outpatients with heart failure. Tex Heart Inst J 2007;34:166169.

38. Pollentier B, Irons SL, Benedetto CM, et al. Examination of the six minute walk test to determine functional capacity in people with chronic heart failure: a systematic review. Cardiopulm Phys Ther J 2010;21:13-21.

39. Singh SJ, Puhan MA, Andrianopoulos V, et al. An official systematic review of the European Respiratory Society/American Thoracic Society: measurement properties of field walking tests in chronic respiratory disease. Eur Respir J2014;44:1447-1478. doi:10.1183/09031936.00150414

40. Holland AE, Spruit MA, Troosters T, et al. An official European Respiratory Society/American Thoracic Society technical standard: field walking tests in chronic respiratory disease. Eur Respir J 2014;44:14281446. doi:10.1183/09031936.00150314

41. Swigris JJ, Olson AL, Shlobin OA, Ahmad S, Brown KK, Nathan SD. Heart rate recovery after six-minute walk test predicts pulmonary hypertension in patients with idiopathic pulmonary fibrosis. Respirology 2011;16:439-445. doi:10.1111/j.1440-1843.2010.01877.x

42. Swigris JJ, Wamboldt FS, Behr J, et al. The 6 minute walk in idiopathic pulmonary fibrosis: longitudinal changes and minimum important difference. Thorax 2010;65:173-177. doi:10.1136/thx.2009.113498

43. Harada ND, Chiu V, Stewart AL. Mobility-related function in older adults: assessment with a 6-minute walk test. Arch Phys Med Rehabil 1999;80:837-841. doi:10.1016/s0003-9993(99)90236-8

44. Carey EJ, Steidley DE, Aqel BA, et al. Six-minute walk distance predicts mortality in liver transplant candidates. Liver Transpl 2010;16:13731378. doi:10.1002/lt.22167 
45. Foroncewicz B, Mucha K, Szparaga B, et al. Rehabilitation and 6-minute walk test after liver transplantation. Transplant Proc 2011;43:3021-3024. doi:10.1016/j.transproceed.2011.08.007

46. VanWagner LB, Uttal S, Lapin B, et al. Use of Six-Minute Walk Test to Measure Functional Capacity After Liver Transplantation. Phys Ther 2016;96:1456-1467. doi:10.2522/ptj.20150376

47. Faustini Pereira JL, Galant LH, Rossi D, et al. Functional Capacity, Respiratory Muscle Strength, and Oxygen Consumption Predict Mortality in Patients with Cirrhosis. Can J Gastroenterol Hepatol 2016;2016:6940374. doi:10.1155/2016/6940374

48. Makhlouf NA, Mahran ZG, Sadek SH, Magdy DM, Makhlouf HA. Sixminute walk test before and after large-volume paracentesis in cirrhotic patients with refractory ascites: A pilot study. Arab J Gastroenterol 2019;20:81-85. doi:10.1016/j.ajg.2019.05.009

49. Casanova C, Cote CG, Marin JM, et al. The 6-min walking distance: long-term follow up in patients with COPD. Eur Respir J 2007;29:535540. doi:10.1183/09031936.00071506
50. Szekely LA, Oelberg DA, Wright C, et al. Preoperative predictors of operative morbidity and mortality in COPD patients undergoing bilateral lung volume reduction surgery. Chest 1997;111:550-558. doi:10.1378/chest.111.3.550

51. De Luca M, Addario L, Lombardi A, et al. Adipopenia Is the Rapid Screening Tool that Best Predicts Mortality in Patients with Decompensated Cirrhosis: Results of a Prospective Study. J Gastroin Liver Dis 2021;30: 94-102. doi:10.15403/jgld-3071

52. Rodrigues SG, Brabandt B, Stirnimann G, Maurer MH, Berzigotti A. Adipopenia correlates with higher portal pressure in patients with cirrhosis. Liver Int 2019;39:1672-1681. doi:10.1111/liv.14175

53. Stolk RP, Wink O, Zelissen PM, Meijer R, van Gils AP, Grobbee DE. Validity and reproducibility of ultrasonography for the measurement of intra-abdominal adipose tissue. Int J Obes Relat Metab Disord 2001;25:1346-1351. doi:10.1038/sj.ijo.0801734

54. Di Ciaula A, Portincasa P. The environment as a determinant of successful aging or frailty. Mech Ageing Dev 2020;188:111244. doi:10.1016/j.mad.2020.111244 